\title{
Modeling the Laser Thermal Therapy in Treatment of Brain Tumors
}

\author{
Mhamed Nour, Mohammed Bougataya, and Ahmed Lakhssassi
}

\begin{abstract}
Due to the restriction of the number of probes that a patient can tolerate and the inaccurate information provided by the invasive temperature measurements, which provide information only at discrete points, a mathematical model simulation is more effective to help physicians in planning their thermal treatment doses. This simulation will maximize therapeutic effects while minimizing side effects. Prior to the treatment, it will provide a precise idea of the predicted reaction depending on selected doses; so new treatment strategies can be proposed and evaluated.

To simulate cerebral circulation [1], we divide the fluid and matter constituents within the human head into several interacting subunits, so called compartments. Four main characteristics of the analyses of the brain model are fluid dynamics analysis, mechanical analysis, laser beam and heat transfer.

The objective of this study is to simulate the Laser Interstitial Thermal Therapy in Treatment (LITT) of brain tumors including all four characteristics described above. The thermal effect of the laser during coagulation lasts around one second and its temperature is between 50 0C and 90 0C. LITT has the following results; the desiccation and retraction of the tissue to destroy tumor phenomena.
\end{abstract}

Index Terms-Laser interstitial thermal therapy, thermal damage, brain cancer, bioheat transfer simulation.

\section{INTRODUCTION}

We will use the following detailed approach while simulating cerebral circulation as described in [1]. We will use several interacting subunits called compartments are used to divide the fluid and matter constituents within the human head.

We also used the abstract model described in [1] which consists of many compartments (see Fig. 1): A - arteries (combined with arterioles), C - capillaries, V - veins (combined with venules), $\mathrm{S}$ - sagittal sinus, $\mathrm{B}$ - brain tissue, F - cerebrospinal fluid, E - extra volume describing brain swelling. The in- and outflows of the system are given by qx, the resistance between compartments $\mathrm{X}$ and $\mathrm{Y}$ by $\mathrm{R}_{\mathrm{XY}}$. The pressure inside a compartment $\mathrm{X}$ is determined by $\mathrm{p}_{\mathrm{X}}$. Compartments, which can vary in size, are described by compliance $\mathrm{C}_{\mathrm{X}(\mathrm{Y}) \text {. }}$

The abstract brain model as described in [1] has two inflows (one for each hemisphere) and two separated

Manuscript received July 1, 2016; revised December 20, 2016.

Mhamed Nour is with Université du Québec en Outaouais, Québec, Canada (e-mail: noum03@uqo.ca).

Mohammed Bougataya and Ahmed Lakhssassi were with Université du Québec en Outaouais, Québec, Canada (e-mail: mohammed.bougataya@uqo.ca, ahmed.lakhssassi@uqo.ca,). vascular beds, which reunite at the compartments describing the sinuses. In addition, both hemispheres (compartments $\mathrm{C}^{\mathrm{L}}$ and $\mathrm{C}^{\mathrm{R}}$ ) contribute to the CSF production.

The main arteries (in-flow of the model) provide Oxygen saturated blood as described in [1] to the brain.

The arteries split up into smaller arteries and arterioles (compartment A), until they finally reach the capillary level (compartment C).

In the capillaries, among other metabolites, oxygen and carbon dioxide are exchanged with the tissue. Furthermore, this is the place where the production of the cerebrospinal fluid (CSF) takes place (internal inflow of compartment F). Then, the capillaries reunite to venules and veins (compartment V) and ultimately end up into the big stiveins called sinuses (compartment S), from where venous blood flows back to the heart (outflow of the model). Within the sagittal sinus the CSF will be absorbed (outflow of compartment F). The arterial system, capillaries, venous system and sinuses are surrounded by brain tissue (compartment B), which itself is surrounded by the CSF. All compartments are enclosed by the cranial bone, which therefore acts as closed compartment. For experimental reasons an extra compartment $\mathrm{E}$ is introduced, which allows the simulation of brain swelling. Additionally, it is possible to simulate the injection of fluid from outside with qI (pressure/volume experiments).

\section{HAEMODYNAMICAL PROCESSES}

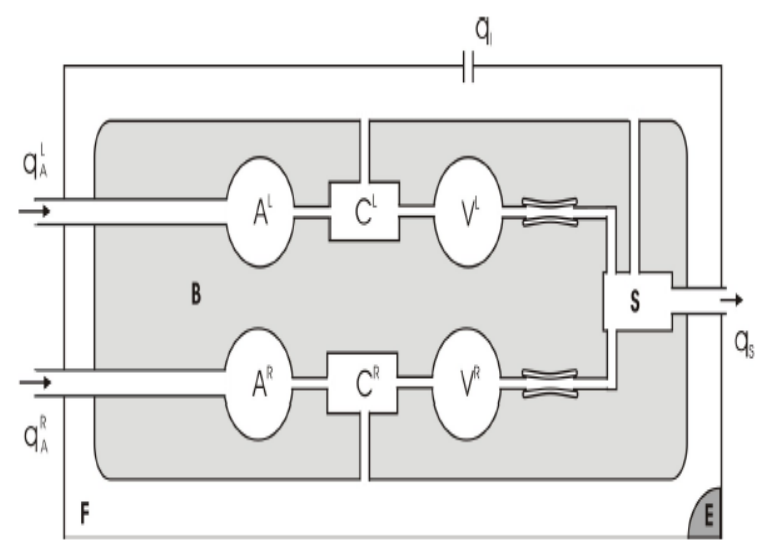

Fig. 1. Abstract model for simulating haemodynamical processes inside the human brain. (Extended model to include both hemispheres). [1]

The aorta and its ramified blood vessels [1] are embedded in biological tissue, specifically the brain tissue. The flowing blood applies pressure to the artery's internal surfaces and its branches, thereby deforming the tissue. The analysis consists of four distinct but coupled procedures: first, a fluid-dynamics analysis including a calculation of the 
velocity field and pressure distribution in the blood (variable in time and in space); second, a mechanical analysis of the deformation of the tissue and artery; third electromagnetic laser beam modelling and fourth thermal distribution and tissue damage during the laser heating of the tumor.

The main characteristics of the analyses are:

1) Fluid dynamics analysis [2] the Navier-Stokes equations are solved in the blood domain. At each surface where the model brings a vessel to an abrupt end, it represents the load with a known pressure distribution.

2) Mechanical analysis [2] only the domains related to the biological tissues are active in this analysis. The model represents the load with the total stress distribution it computes during the fluid-dynamics analysis.

3) - Laser beam modeling [3]. We will model the lasertissue interaction with Beer-Lambert Law.

4) - Thermal conduction (based on either Fourier's law or modified Fourier's law), constant blood perfusion and evaporation as a boundary condition. The Heat Transfer Module will be used with a material library model for brain and probe solid materials.

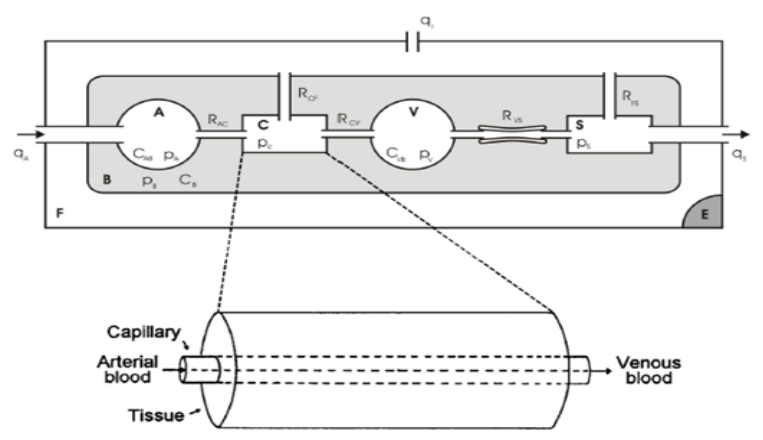

Fig. 2. Connection between compartment model and oxygen transport. [1]

COMSOL Multiphysics Simulation Software will be used to simulate the mathematical model which includes The Brain material with tumors. These materials will be defined with their density, conductivity, specific heat, diffusivity, relative permittivity, relative permeability and electrical conductivity values. A new material Laser delivery probe will also be defined as the source energy.

Expected results are thermal distribution throughout the biological tissues during the heating and temperature distribution. We will also compare thermal conduction results on Fourier's law vs. modified Fourier's law. An expected result is the estimation of the volume of tissues damaged during the treatment.

Furthermore predicting the result of the laser interstitial thermal therapy in treatment of brain cancer depending on scenarios discussed between physicians and patients will improve the health care system by providing a personalized and focused treatment. Using the laser energy source, light is emitted from the diffusive tip of an optical fiber probe that is inserted into the center of a brain tumor

Using COMSOL v5.2, we build apps for physicians' use. Our COMSOL Multiphysics model is turned into an application with its own interface using the tools provided with the Application Builder desktop environment. Physicians will use their laptops or smart phones to access and run the application remotely.

\section{MATERALS AND METHODS}

\section{A. Simulation Model}

The ACVS (Fig. 1) is inside a brain tissue. The brain tissue (Fig. 2) is modeled as a Cylinder of $160 \mathrm{~mm}$ width, 210 depth, and $80 \mathrm{~mm}$ height. The cranial bone (Fig. 3) is of 210 width, $235 \mathrm{~mm}$ depth and $90 \mathrm{~mm}$ height.

The Brian tissue, as shows in Fig. 3, is heated up to 10 seconds by a $5 \mathrm{~W}$ laser.

The initial temperature of the brain tissues is considered $293.15 \mathrm{~K}$.

These values can be changed by the user of the model to simulate in real-time.

\section{B. Laser Procedure}

We will model the laser-tissue interaction (Fig. 3.) with Beer-Lambert Law [3]. The Beer-Lambert law can be written in differential form for the light intensity I as:

$$
\partial \mathrm{I} / \partial \mathrm{x}=\alpha(\mathrm{T}) \mathrm{I}
$$

where $\mathrm{x}$ is the coordinate of the material, $\alpha(T)$ is the temperature-dependent absorption coefficient of the tissue.

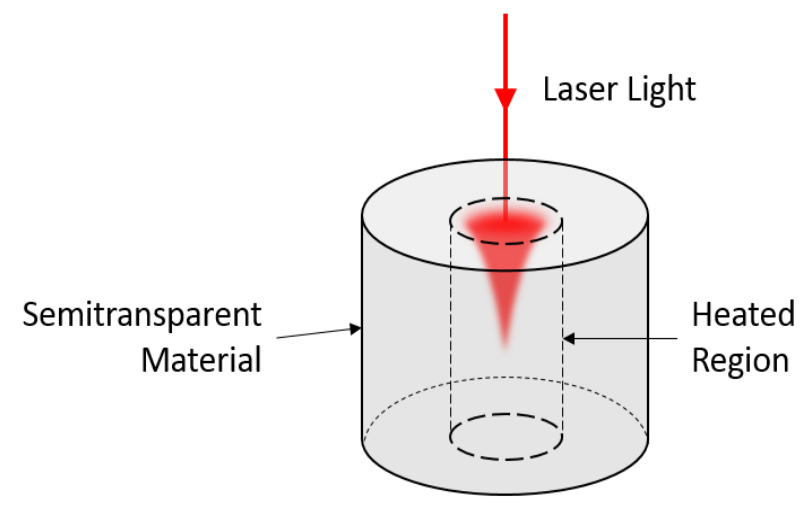

Fig. 3. Modelisation of the neer-Lambert law. [3]

\section{Modeling in COMSOL Multiphysics}

\section{C.1 Geometrical description of the model}

We will start with the thermal conduction using Fourier's law for our first step of the simulation (results presented here) then upgrade to the modified Fourier's law [4]. We will then compare the results of these two simulations.

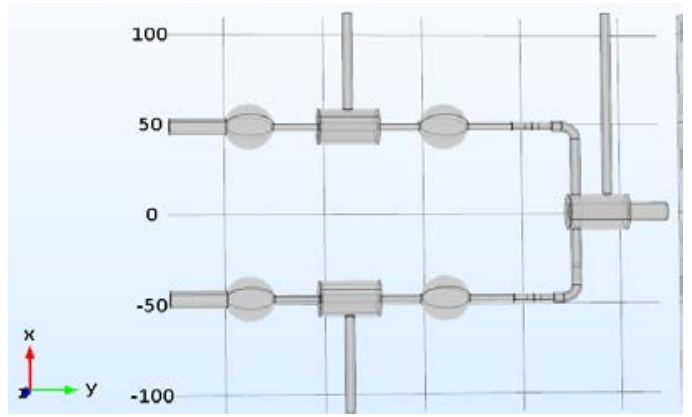

Fig. 4. The model domain consists of part of the aorta, its branches, and the surrounding tissue. 


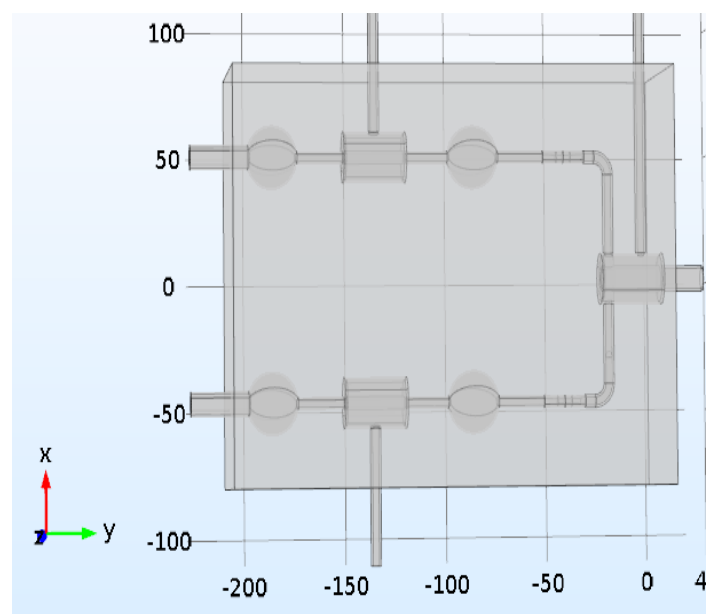

Fig. 5. The model domain consists of part of the aorta, its branches, and the surrounding tissue. [Added on the top the brain tissue].

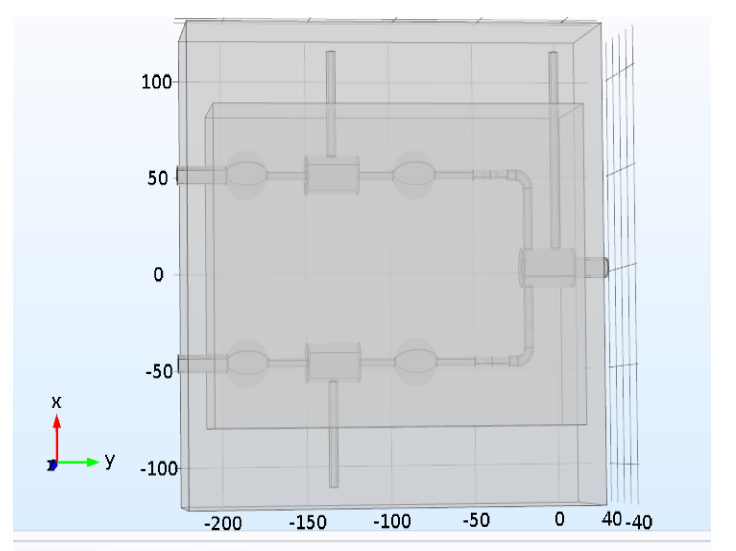

Fig. 6. The model domain consists of part of the aorta, its branches, and the surrounding tissue. [Added on the top of the brain tissue, the cranial bone].

\section{C.2. Heat distribution}

The LITT of Brain Tumors [5], [6] was modeled by the bio-heat equation in a 3D geometric study, using the bioheat transfer application mode with time dependent COMSOL 5.2. Table I describes the physical parameters used by our Comsol numerical simulation.

\section{C.2.1. Heat Equation (mathematical model)}

We will start with the thermal conduction using Fourier's law for our first step of the simulation (results presented here) then upgrade to the modified Fourier's law.

$$
\begin{gathered}
\rho \mathrm{C}_{\mathrm{p}} \frac{\partial \mathrm{T}}{\partial \mathrm{t}}+\rho \mathrm{C}_{\mathrm{p}} \mathrm{u} \cdot \nabla \mathrm{T}+\nabla \mathrm{q}=\mathrm{Q}+\mathrm{Q}_{\mathrm{bio}} \\
\mathrm{q}=-\mathrm{k} \nabla \mathrm{T}
\end{gathered}
$$

where $\mathrm{T}$ is temperature $(\mathrm{K}), C_{P} C_{P}$ is the heat capacity $\left.\mathrm{J} /\left(\mathrm{kg}^{*} \mathrm{~K}\right)\right), \quad p$ is the density of the brain tissue $\left(\mathrm{kg} / \mathrm{m}^{\wedge} 3\right), \mathrm{k}$ is the thermal conductivity of brain tissue $(\mathrm{W} /(\mathrm{m} * \mathrm{~K})), Q$ is heat source, $Q_{b i o}$ is the perfusion and metabolic heat source.

\section{C.2.2.The perfusion equation}

$$
Q_{\mathrm{bio}}=p_{b} C_{b} w_{\mathrm{b}}\left(T_{b}-T\right)+Q_{m e t}
$$

where $Q_{\text {bio }}$ is the perfusion and metabolic heat source, $p_{b} p_{b}$ is the blood Density, $C_{b}$ is Specific blood heat,
$Q_{\text {met }}$ is Metabolic heat source, $w_{b}$ is Blood perfusion rate, $T_{b}$ is the blood flow rate, $\mathrm{T}$ is time (s), $Q_{m e t}$ is the metabolic heat source.

TABLE I: SETTINGS OF QBIO PARAMETERS.

\begin{tabular}{|l|l|}
\hline Description & Value \\
\hline Arterial blood temperature & $310.15[\mathrm{~K}]$ \\
\hline Specific heat, blood & $3650[\mathrm{~J} /(\mathrm{kg} * \mathrm{~K})]$ \\
\hline Blood perfusion rate & $0.866[\mathrm{l} / \mathrm{s}]$ \\
\hline Density, blood & $1035 \mathrm{~kg} / \mathrm{m}^{3}$ \\
\hline Metabolic heat source & 0 \\
\hline
\end{tabular}

We consider that the metabolic heat and external heat sources are negligible in respect to the laser inducted heat.

The initial temperature of the brain tissues was considered as $\mathrm{T}_{0}=293.15 \mathrm{~K}$.

The thermo-optical parameters were considered constant during the thermal process.

MATERIALS The following material properties are used: - Blood

- density = $1060 \mathrm{~kg} / \mathrm{m} 3$

- dynamic viscosity $=0.005 \mathrm{Ns} / \mathrm{m} 2$

- Artery

- density $=960 \mathrm{~kg} / \mathrm{m} 3$

- Neo-Hookean hyperelastic behavior: the coefficient $\mu$ equals $6.20 \cdot 106 \mathrm{~N} / \mathrm{m} 2$, while the bulk modulus equals $20 \mu$ and corresponds to a value for Poisson's ratio, $v$, of 0.45 . An equivalent elastic modulus equals $1.0 \cdot 107 \mathrm{~N} / \mathrm{m} 2$.

- Brain tissue

\section{- Density = $1050 \mathrm{~kg} / \mathrm{m} 3$}

- Neo-Hookean hyperelastic behavior: the coefficient $\mu$ equals $7.20 \cdot 106 \mathrm{~N} / \mathrm{m} 2$, while the bulk modulus equals $20 \mu$ and corresponds to a value for Poisson's ratio, $v$, of 0.45 . An equivalent elastic modulus equals $1.16 \cdot 106 \mathrm{~N} / \mathrm{m} 2$.

\section{C.3. Mesh}

The brain tissue is meshed using a triangle swept mesh as shown in Fig. 7.

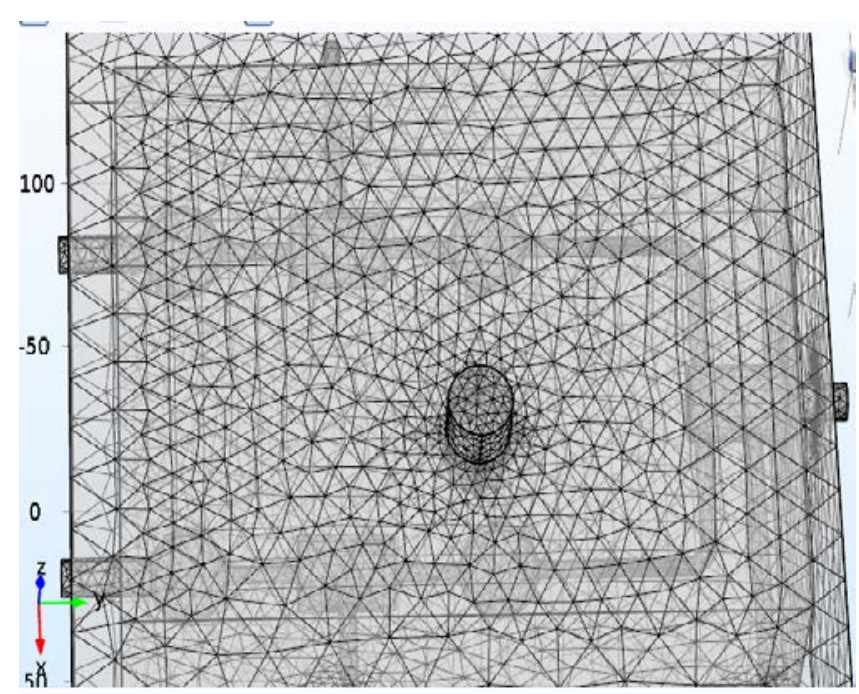

Fig. 7. Mesh of the model simulation. 


\section{C.4. Thermal damage}

The induced damage (or damage integral) has been computed using well-established first order Arrhenius equation [3]:

$$
\Omega(\mathrm{t})=\ln \frac{\mathrm{C}_{0}}{\mathrm{C}_{\mathrm{UD}}(\mathrm{t})}=\int \operatorname{Aexp}\left[-\frac{\mathrm{E}_{\mathrm{a}}}{\mathrm{RT}(\mathrm{t})}\right]_{\mathrm{dt}}
$$

where $\mathrm{C}_{0}$ is the original concentration of undamaged cells, $\mathrm{C}_{\mathrm{UD}} \mathrm{C}_{\mathrm{UD}}$ is the concentration of the remaining living cells after time $t$, the treatment time, $\mathrm{A}$ is the frequency factor, $\mathrm{E}_{\mathrm{a}}$ is the activation energy and $\mathrm{R}$ is the universal gas constant. $\left(\mathrm{R}=8.314 \mathrm{~J} \mathrm{~mol}^{-1} \mathrm{~K}^{-1}\right)$.

A damage integral of $\Omega=1$, corresponds to $63 \%$ percent probability of cell death, and damage integral of $\Omega=4.6$, corresponds to $99 \%$ percent probability of cell death at a specific point.

TABle II: THE PhySiCAL PARAMETERS USED IN OUR COMSOL NUMERICAL Simulation. (THERMAL PROPERTIES OF BRAIN)

\begin{tabular}{|l|l|l|l|}
\hline Name & Expression & Value & Description \\
\hline $\mathrm{r}_{\text {mat }}$ & $1[\mathrm{in}]$ & $0.0254 \mathrm{~m}$ & material inner radius \\
\hline Thickness & $25400[\mathrm{um}]$ & $0.0254 \mathrm{~m}$ & mat inner thickness \\
\hline $\mathrm{r}_{\text {spot }}$ & $8[\mathrm{~mm}]$ & $0.008 \mathrm{~m}$ & Radius of laser spot size \\
\hline plaser & $5[\mathrm{~W}]$ & $5 \mathrm{~W}$ & Laser power \\
\hline Temp & $310.15[\mathrm{~K}]$ & $310.15 \mathrm{~K}$ & Initial Temperature \\
\hline $\begin{array}{l}\text { Heat } \\
\text { Capacity }\end{array}$ & $\begin{array}{l}3636[\mathrm{~J} /(\mathrm{kg} * \\
\mathrm{K})]\end{array}$ & $\begin{array}{l}3636[\mathrm{~J} /(\mathrm{kg} \\
* \mathrm{~K})]\end{array}$ & Brain Heat Capacity \\
\hline Density & $\begin{array}{l}1050\left[\mathrm{~kg} / \mathrm{m}^{\wedge}\right. \\
1050[\mathrm{~kg} / \mathrm{m}\end{array}$ & $\begin{array}{l}\wedge 3] \\
\wedge \text { Brain Density }\end{array}$ \\
\hline $\begin{array}{l}\text { Thermal } \\
\text { conductivity }\end{array}$ & $\begin{array}{l}0.51[\mathrm{~W} /(\mathrm{m} * \\
\mathrm{K})]\end{array}$ & $\begin{array}{l}0.51[\mathrm{~W} /(\mathrm{m} \\
* \mathrm{~K})]\end{array}$ & $\begin{array}{l}\text { Brain } \\
\text { conductivity }\end{array}$ \\
\hline A & $7.39 \mathrm{e} 39[1 / \mathrm{s}]$ & $7.39 \mathrm{e} 39$ & Frequency factor \\
\hline dE & $\begin{array}{l}2.577 \mathrm{e} 5[\mathrm{~J} / \mathrm{m} \\
\mathrm{ol}]\end{array}$ & $\begin{array}{l}2.577 \mathrm{e} 5 \\
\text { Activation energy }\end{array}$ & \\
\hline
\end{tabular}

\section{Simulation Results}

During the simulation and in order to minimize the side effects while optimizing the laser treatment, the physician can play with the input values to Control the thermal ablation during a laser surgery/cancer treatment.

Fig. 8 and Fig. 9 show the heat distribution during the simulation which will help physicians to predict and organize the treatment.

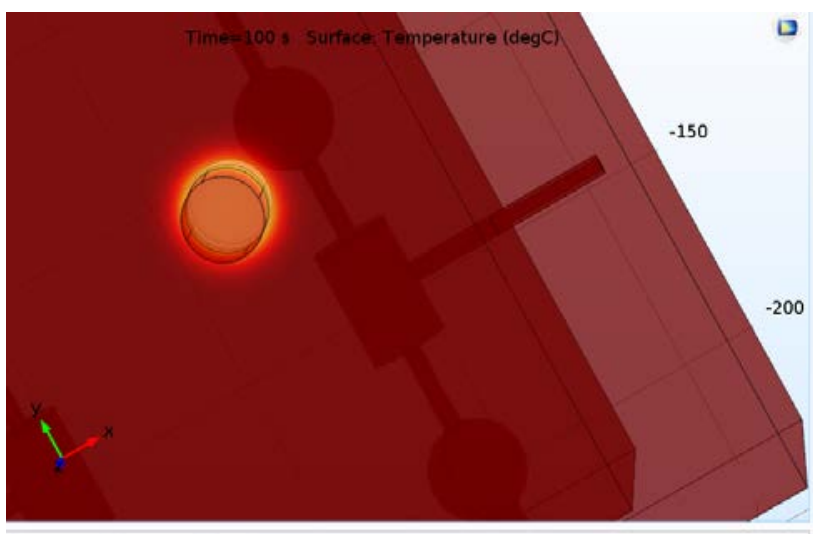

Fig. 8. Temperatre during 15 seconds at the surface of the brain tissue.

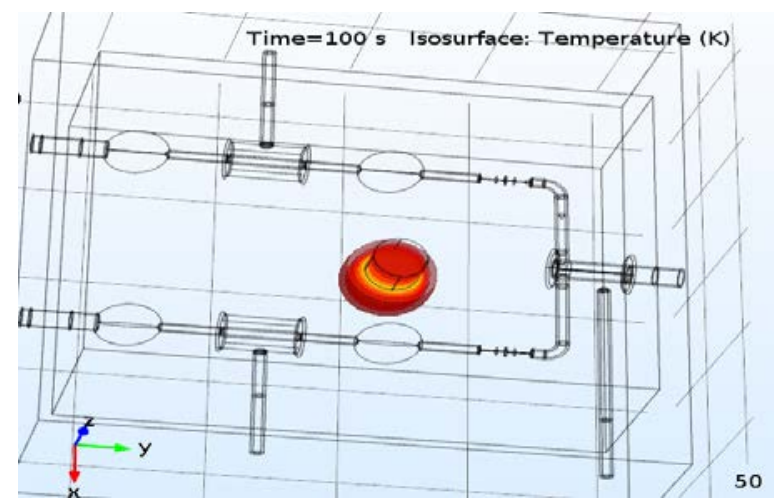

Fig. 9. Temperatre during 15 seconds at the surface of the brain tissue (isothermal contours (ht)).

Such model shows also the impact of the thermal damaged tissues during the simulation.

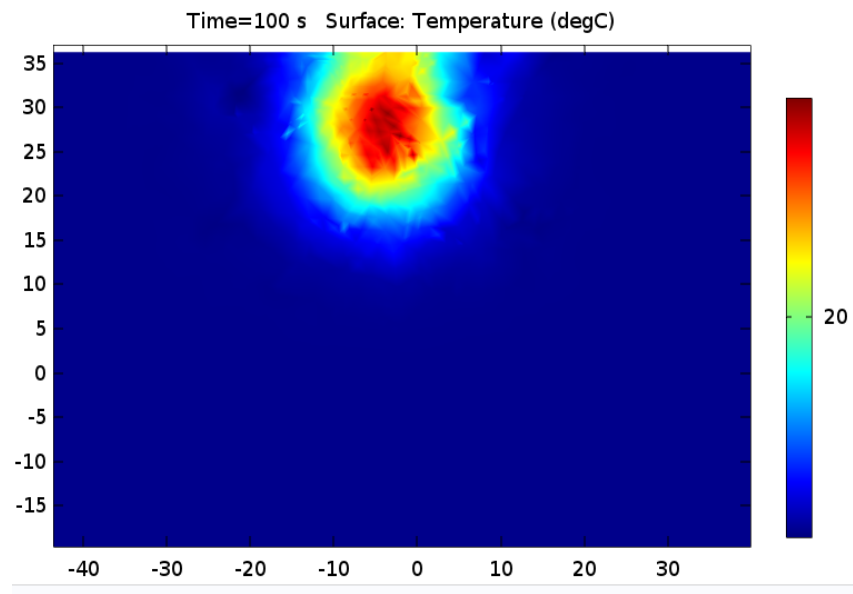

Fig. 10. Volume: Fraction of necrotic tissue, smoothing (1).

To order to evaluate the optimal power and treatment time to complete the tumor necrosis, a detailed heating simulation can be performed by varying the power for different tumor diameters. Fig. 10 shows the fraction of the necrotic tissue.

A main objective is to make sure that the impact of the thermal damaged tissues during the simulation is inside the tumor tissue zone with ideally no impact to the healthy brain tissue.

\section{APPS FOR PHYSICIANS' USE}

Using Comsol v5.3, we build apps for physicians' use. Our COMSOL Multiphysics model is turned into an application with its own interface using the tools provided with the Application Builder desktop environment. Physicians will use their laptops or smart phones to access and run the application remotely (Fig. 11 and Fig. 12).

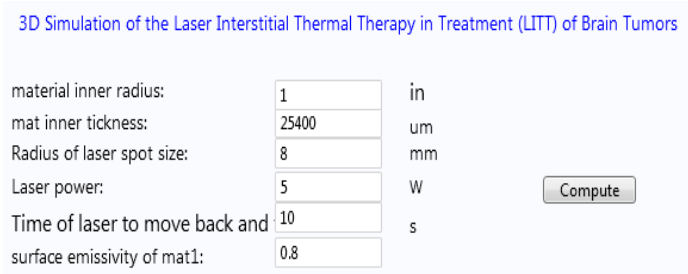

Fig. 11. The Output of the Apps. You enter the parameters, select compute to execute your simulation in real-time. 

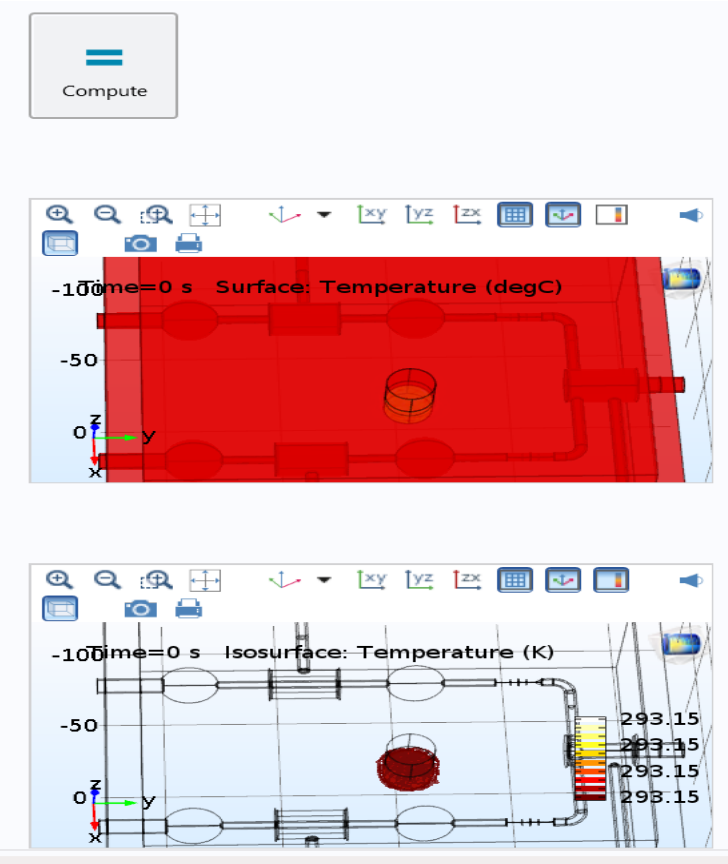

Fig. 12. The Output from the Apps after the user select compute.

\section{CONCLUSION}

Controlled thermal ablation is a big challenge during a laser surgery/cancer treatment. A tool to help physicians predict and organize the treatment will be helpful.

In this paper, we proposed a simulation model of the LITT with physicians' interaction via Comsol Apps. Such model shows the impact of the heat distribution and thermal damage of the tissue during the simulation.

\section{REFERENCES}

[1] M. Bohm, Mathematical modeling of human brain physiological.

[2] Halcyon. [Online].

http://www.halcyon.com/pub/journals/21ps03-vidmar

[3] Fluid-structure interaction in a network of blood vessels. [Online]. Available:

https://www.comsol.com/model/download/283731/models.sme.blood _vessel.pdf

[4] $\bar{S}$. Singh and R. Repaka, "Pre-clinical modelling and simulation of hepatic radiofrequency ablation," in Proc. of the Comsol 2015. Conference in Pune.

[5] M. M. Tung, M. Trujillo, J. A. Lopez Molina, M. J. Rivera, and E. J. Berjano, "Modeling the heating of biological tissue based on the hyperbolic heat transfer equation," Universidad Politecnica de Valencia, Valencia, Spain. Physics. med-ph, Nov. 20, 2008.

[6] A. M. Mohammadi and J. L. Schroeder, "Laser Interstitial thermal therapy in treatment of brain tumors - the NeuroBlate System, 2014," Informa, UK Ltd.

[7] R. Tyc and K. J. Wilson, "Laser surgery/cancer treatment: Real-time interactivity enhances interstitial brain tumor therapy," BioOptics World, May 2010.

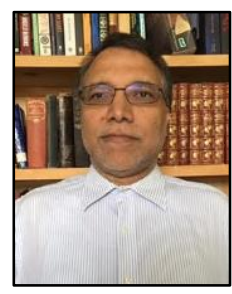

Mhamed Nour rceived the B. Ing. in computer science from INSAE, Rabat, Morocco in 1984, and a M.Sc.A in computer science in software engineering from Université du Montrèal (UdeM), Québec, Canada in 1994. He also did research on the distributed algorithms for multi-media routing with QoS constraints at CRIM (Centre de Recherche Informatique de Montreal) and UdeM. He is currently a PhD Student at Université du Québec en Outaouis (UQO), Québec, Canada.

Mhamed taught computer science for more than 20 years and has been working as a senior network analyst since 1996. His research activities focus on the heat transfer mechanisms in biological tissues for thermal treatment practices and the development of algorithms for automatic bio dosimetry for tumor laser treatment.

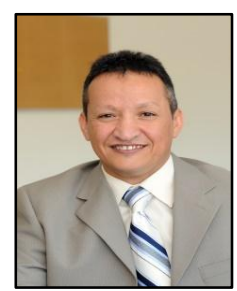

Mohmmed Bougataya received the B.Ing. in electrical engineering from USTO University, Oran, Algeria in 1998. He also received the M.Sc.A., and $\mathrm{Ph} . \mathrm{D}$. in electrical engineering from Université du Québec (UQTR) Québec, Canada in 2003 and 2010 respectively. Dr Bougataya worked as associate professor of electrical engineering at department of computer Science and Engineering at the University of Quebec in CANADA since 2012 with interests in heat transfer mechanisms in biological tissues for thermal treatment practices, thermal mechanical stress in electronic packaging and developing algorithms for microsystems thermo-mechanical monitoring and associated distributed sensors network. His research contributions have been acknowledged by the scientific community and been used to write patent applications. He also has a considerable industrial R \& D experience between 2000 and 2010 with Hyperchip Inc and DreamWafer design group at TechnoCap Inc. Bougataya has personally designed and managed the design of cooling solutions and thermo mechanical stress for a wide range of electronics, including computers, servers, routers, switches, power electronics and reconfigurable PCB's, as well as other networking and telecommunication systems. Dr Bougataya is the author/co-author of more than 80 scientific publications and research report. Professor Bougataya is a member of APCBEES, IEEE and OIQ

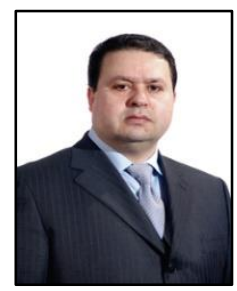

Ahmed Lakhssassi received the B.Ing. and M.Sc.A in electrical engineering from Université du Québec (UQTR), Québec, Canada in 1988 and 1990 respectively. He also received the Ph.D. in energy and material sciences in 1995 from INRS-Énergie et Matériaux Monteal, Québec, Canada. A year also, he had become a professor of Electro-thermomechanical aspects at NSERC -Hydro-Quebec industrial research chair at Electrical Engineering Department of the UQTR. Since 1998, he has been with UQO (Université du Québec en Outaouais), where he is currently titular professor and responsible of the LIMA laboratory LIMA (Advanced Microsystem Engineering Laboratory) developing algorithms for Microsystems thermomechanical monitoring and associated distributed sensors network. His research activities focus on the development of embedded algorithms for bio-implantable Microsystems, heat transfer mechanisms in biological tissues for thermal treatment practices. He is the author/co-author of more than 150 scientific publications and research report, and thesis advisor of 60 graduate and undergraduate students who completed their studies. Professeur Lakhssassi is a member of ReSMiQ, Nano-Québec, IEEE and OIQ. 